Polymer Journal, Vol. 39, No. 7, pp. 659-669 (2007)

(C) 2007 The Society of Polymer Science, Japan

\title{
Photoinduced Holographic Gratings in Azobenzene-Functionalized Poly(amideimide)s
}

\author{
Ewa Schab-BalcerzaK,,$^{1, \dagger}$ Anna Sobolewska, ${ }^{2}$ Andrzej Miniewicz, ${ }^{2}$ \\ Jan JURUSIK, ${ }^{1}$ and Bozena JARZABEK ${ }^{1}$ \\ ${ }^{1}$ Centre of Polymer and Carbon Materials, Polish Academy of Sciences, 34 M. Curie-Sklodowska Str., 41-819 Zabrze, Poland \\ ${ }^{2}$ Institute of Physical and Theoretical Chemistry, Wroclaw University of Technology, 50-370 Wroclaw, Poland
}

(Received February 2, 2007; Accepted March 25, 2007; Published May 9, 2007)

\begin{abstract}
We present the diffraction grating recording in a series of poly(amideimide)s functionalized with methyl-substituted azobenzene chromophore as side group and correlate the results with the molecular structure. Poly(amideimide)s, differing in their backbone structure and in position in which azobenzene group is attached to polymer chain, were synthesized and characterized by the spectroscopic methods. Diffraction gratings were fabricated using degenerate two-wave mixing technique with $\mathrm{cw} \mathrm{Ar}^{+}$laser working at $\lambda=514.5 \mathrm{~nm}$ and monitored by light diffraction of low power He-Ne probe beam $\lambda=632.8 \mathrm{~nm}$ in a transmission mode. Two qualitatively different configurations of the recording beam polarizations were used $s-s$ and $s-p$. The dynamics of diffraction grating inscription was described by mono- or biexponential growth functions. The surface relief grating formation was also examined in poly(amideimide)s. They were studied by atomic force microscope and revealed the strong dependence on the writing beams polarization. Additionally the thermal stability of the photoinduced surface gratings was checked. [doi:10.1295/polymj.PJ2006227]

KEY WORDS Azopolymers / Polyimides / Diffraction Gratings / Surface Relief Gratings /
\end{abstract}

Recent years are characterized by an ever-growing interest in the new photosensitive materials which are able to change their optical properties under light irradiation. ${ }^{1}$ Studies on polymers containing azobenzenetype chromophores, often called azopolymers, represent a very active research field in the past few decades. Azobenzene chromophores have been incorporated into polymer structure in variety configurations by a number of different synthetic approaches. ${ }^{2}$

The presence of the $-\mathrm{N}=\mathrm{N}-$ photochromic group in azopolymers provides its sensitivity to the light. The light-induced modification of photochromic azopolymers is very promising for optical information storage, fabrication of diffractive optical elements and other photonics devices. ${ }^{3-7}$ All of these applications are based on one of the most important and known properties of azobenzene, i.e., reversible trans-cis photochemical isomerization. This photoisomerization induces conformational changes in the polymer chain, which in turn lead to macroscopic variation in the chemical and physical properties of polymeric material. The irradiation with a linearly polarized light generates the optical anisotropy as a result of perpendicular alignment of azobenzene molecules to the actinic electric field vector. ${ }^{8}$ This phenomenon has been first time reported in 1984 by Todorov et al. ${ }^{9}$ Photoinduced anisotropy produces optical dichroism and birefringence in various materials. Another result of the photoisomerization under conditions of spatially peri- odic light illumination is respective modification of the film surface, which is called the surface relief grating. The first inscriptions of surface relief gratings (SRGs) have been independently reported in 1995 by Rochon et al. ${ }^{10}$ and Kim et al. ${ }^{11}$ Over the past years, the discovery of SRG has sparked off intense research effort into design and synthesizing new polymers for SRG formation. Typically, SRG is formed when a thin polymer film is exposed to an interference pattern produced by two coherent laser beams of appropriate polarization, as a result of mass transport close to the polymer surface. ${ }^{12}$ The SRG formation is unique to azobenzene polymers. ${ }^{5}$ SRGs may be photoinscribed with amplitude modulation ranging from a few nanometers up to the micrometer scale. ${ }^{13}$ Therefore, the formation of controlled topographic gratings has many interesting applications in the fast expanding area of nanotechnology. Fabrication of various complex diffractive optical elements such as infrared waveplates, grating filters, waveguide couplers, slanted SRG for planar optical interconnects and high efficiency gratings for laser applications represent one aspect of their uses. ${ }^{14-16}$

Most systems employed for SRG formation comprise azopolymers in which the chromophore is covalently attached either as a side-chain or in the main-chain, in the form of thin, spin-coated or casted films. ${ }^{17}$

It has been shown that the photoresponsive behavior of polymers strongly depends on various chemical

${ }^{\dagger}$ To whom correspondence should be addressed (Tel: +48-32-273-2214, Fax: +48-32-271-2969, E-mail: ewabalce@cchp-pan.zabrze.pl). 

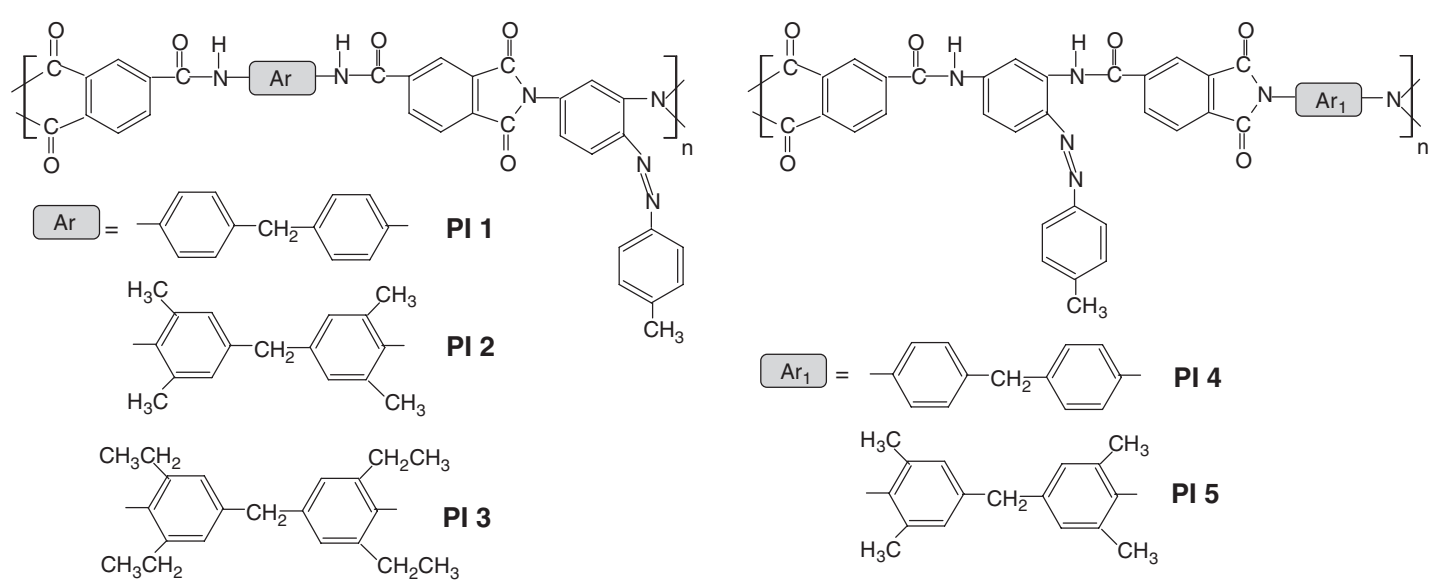

Figure 1. Chemical structures of investigated polyimides.

structure factors of azopolymers. They include: molecular structure of azobenzene derivative, the spacer length, the content of photochromic moieties, ${ }^{7}$ the rigidity of polymer main chain and the interaction between chromophore and the main chain, ${ }^{18}$ and finally experimental conditions as well. In an effort to increase the stability of photoinduced birefringence and to generate highly efficient surface relief gratings, new azopolymers are being designed and synthesized. Thus the systematically performed study of the structure-property relationship of azobenzene-functionalized polymers are desired to guide the rational design of polymers for photonics devices. To date, photoinduced effect such as dichroism, birefringence and formation of diffraction and surface relief gratings have been studied in various types of azopolymers. ${ }^{19}$ However, little information on the relationship between kinetics of diffraction grating and surface relief gratings and structure of polyimides bearing azobenzene group can be found in the literature so far. ${ }^{20}$ Polyimides (PI) based on aromatic ring structures or their copolymers are well known as high performance polymers, by virtue of their excellent thermal and thermooxidative stabilities, outstanding mechanical and electrical properties, and superior chemical resistance, have secured a permanent place in a variety of industrial applications..$^{21,22}$ The light induced properties of PI, mainly due to their good thermal stability, cause the polyimides bearing azobenzene group have been used in the design of photorefractive and second-order nonlinear optical (NLO) materials. ${ }^{23,24}$ In a recent few years our research has been focused on the study of the influence of the chemical structure of azobenzene functionalized polyimides on photoinduced dichroism and birefringence both related with diffraction grating inscription. ${ }^{25-31}$ This work is part of a continuing study of the relationship between polyimide structure and their photoinduced properties.

In present paper we investigated the formation of dif- fraction gratings in new synthesized azobenzene functionalized poly(amideimide)s. Their azobenzene group is identical, but there are differences in the main chain architecture. The effect of backbones on the inscription rates and saturation levels of the diffraction grating formation in these polymers have been studied and discussed. The ability to surface relief grating formation and its thermal stability were also examined in these poly(amideimide)s.

\section{EXPERIMENTAL}

\section{Materials}

Chemicals and solvents were purchased from Aldrich and used as received. Detailed synthesis and characterization of the poly(amideimide)s PI 1-PI 3 (Figure 1) have been reported previously. ${ }^{25}$ Poly(amideimide)s PI 4 and PI 5 (Figure 1) are new and were prepared from the newly synthesized diamidedianhydride (DA) and 4,4'-methylenedianiline and 4,4'-methylene bis(2,6-dimethylaniline), respectively. The monomer DA was prepared as reported in our previous paper for different dianhydrides (Scheme 1). ${ }^{32}$ To a $100 \mathrm{~mL}$ flask equipped with magnetic stirrer, condenser and dropping fuel was charged $22 \mathrm{mmol}$ of trimellitic anhydride chloride (TMACl) and $25 \mathrm{~mL}$ of dry acetone. After the mixture was heated under reflux, a solution of $10 \mathrm{mmol}$ 2,4-diamino4 '-methylazobenzene and $22 \mathrm{mmol}$ of dry pyridine in $25 \mathrm{~mL}$ of acetone were added dropwise for $30 \mathrm{~min}$. The mixture was stirred and heated under reflux for $1 \mathrm{~h}$. After cooling to room temperature, the resulting precipitate was filtered off and washed with methanol and then dried in $60^{\circ} \mathrm{C}$. The crude product was washed with hot acetic anhydride and dried in vacuum at $150^{\circ} \mathrm{C}$, (yield: $50 \%$ ). mp $190^{\circ} \mathrm{C}$. UV-Vis (NMP): $\lambda_{\max }=262,298,391 \mathrm{~nm}\left(\varepsilon_{391}=15.3 \times 10^{3}, \varepsilon_{514.5}=\right.$ $\left.0.475 \times 10^{3} \mathrm{Lmol}^{-1} \mathrm{~cm}^{-1}\right)$.

IR $\left(\mathrm{KBr}, \mathrm{cm}^{-1}\right)$ : 1853, 1777, $(\mathrm{C}=\mathrm{O}$ in anhydride $)$, 


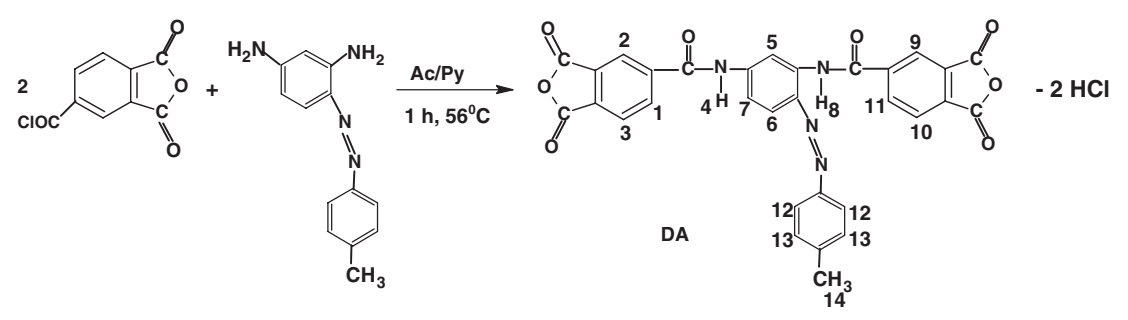

Scheme 1. Synthesis of the diamidedianhydride DA.

$1682(\mathrm{C}=\mathrm{O}$ in amide $), 2922\left(\mathrm{CH}_{3}\right)$. Anal. Calcd for $\mathrm{C}_{31} \mathrm{H}_{18} \mathrm{~N}_{2} \mathrm{O}_{8}$ : C, 64.81\%; H, 3.16\%; N, 9.75\%. Found: C, 64.48\%; H, 3.30\%; N, 9.46\%. ${ }^{1} \mathrm{H}$ NMR (DMSO$\left.d_{6}, \delta, \mathrm{ppm}\right): 2.37\left(\mathrm{~s}, 3 \mathrm{H}, \mathrm{CH}_{3}, \mathrm{H}_{14}\right), 7.37$ (d, $\mathrm{ArH}$, $\left.2 \mathrm{H}, \mathrm{H}_{13}\right), 7.83$ (dd, $\left.\mathrm{ArH}, 1 \mathrm{H}, \mathrm{H}_{7}\right), 7.89(\mathrm{~d}, \mathrm{ArH}, 1 \mathrm{H}$, $\left.\mathrm{H}_{6}\right), 7.91\left(\mathrm{~d}, \mathrm{ArH}, 2 \mathrm{H}, \mathrm{H}_{12}\right), 8.23\left(\mathrm{~d}, \mathrm{ArH}, 1 \mathrm{H}, \mathrm{H}_{3}\right)$, $8.27\left(\mathrm{~d}, \mathrm{ArH}, 1 \mathrm{H}, \mathrm{H}_{10}\right), 8.51\left(\mathrm{~d}, \mathrm{ArH}, 1 \mathrm{H}, \mathrm{H}_{9}\right), 8.53$ (dd, ArH, 1H, $\left.\mathrm{H}_{1}\right), 8.63$ (d, ArH, 1H, $\left.\mathrm{H}_{5}\right), 8.84$ (dd, $\mathrm{ArH}, 1 \mathrm{H}, \mathrm{H}_{11}$ ), 11.09 (s, NH, 1H, H $\left.\mathrm{H}_{4}\right) 11.37$ (s, $\mathrm{NH}, 1 \mathrm{H}, \mathrm{H}_{8}$ ).

Polymers PI 4 and PI 5 were prepared following the procedure described in literature. ${ }^{25}$ The polymers were characterized with FT-IR, ${ }^{1} \mathrm{H}$ NMR spectroscopes and elemental analysis.

PI 4: $\mathrm{IR}\left(\mathrm{KBr}, \mathrm{cm}^{-1}\right)$ : $1777,1719(\mathrm{C}=\mathrm{O}$ in imide $)$, 1374 (C-N str.), $722(\mathrm{C}=\mathrm{O}$ bending), $1681(\mathrm{C}=\mathrm{O}$ amide), $3032\left(-\mathrm{CH}_{3}\right), 3357(\mathrm{~N}-\mathrm{H})$. Anal. Calcd: $\mathrm{C}$, 71.73\%; H, 3.83\%; N, 11.41\%. Found: C, 71.06\%; $\mathrm{H}, 4.0 \% ; \mathrm{N}, 11.38 \% .{ }^{1} \mathrm{H}$ NMR (DMSO- $d_{6}, \delta, \mathrm{ppm}$ ): 2.40 (s, 3H, $\mathrm{CH}_{3}$,), 3.84 (s, $\left.\mathrm{CH}_{2}, 2 \mathrm{H},\right), 6.55$ (d, $\mathrm{ArH}$, 4H,), 6.91 (d, ArH, 2H,), 7.31 (dd, ArH, 1H,), 7.36 (d, ArH, 1H,), 7.39 (d, ArH, 2H,), 7.46 (d, ArH, 4H,), $7.82(\mathrm{~d}, \mathrm{ArH}, 1 \mathrm{H}),, 7.85(\mathrm{~d}, \mathrm{ArH}, 1 \mathrm{H}),$, (d, ArH, 1H,) 8.15 (dd, ArH, 1H,), 8.51 (d, ArH, 1H,), 8.90 (dd, ArH, 1H,), 10.88 (s, NH, 1H,), 11.32 (s, NH, 1H,). UV-Vis (NMP): $\lambda_{\max }=267,346$, $407, \quad 447 \quad\left(\varepsilon_{447}=5.99 \times 10^{3}, \quad \varepsilon_{514.5}=0.88 \times 10^{3}\right.$ $\left.\mathrm{Lmol}^{-1} \mathrm{~cm}^{-1}\right)$.

PI 5: IR ( $\left.\mathrm{KBr}, \mathrm{cm}^{-1}\right)$ : $1779,1723(\mathrm{C}=\mathrm{O}$ in imide $)$, 1370 (C-N str.), $726(\mathrm{C}=\mathrm{O}$ bending $), 1686(\mathrm{C}=\mathrm{O}$ in amide), $2923\left(-\mathrm{CH}_{3}\right), 3329(\mathrm{~N}-\mathrm{H})$. Anal. Calcd: C, $71.42 \%$; H, 4.79\%; N, 11.10\%. Found: C, 69.91\%; $\mathrm{H}, \quad 4.83 \% ; \mathrm{N}, 10.90 \%$. ${ }^{1} \mathrm{H}$ NMR (DMSO- $d_{6}, \delta$, ppm): 2.08 (s, 12H, $\mathrm{CH}_{3}$ ), 2.39 (s, 3H, $\left.\mathrm{CH}_{3},\right), 3.97$ (s, $\left.\mathrm{CH}_{2}, 2 \mathrm{H},\right), 7.18$ (s, ArH, 4H,), 7.36 (d, ArH, 2H,), 7.83 (dd, ArH, 1H,), 7.85 (d, ArH, 1H,), 7.92 (d, ArH, 2H,) 8,14 (d, ArH, 1H,), 8.21 (d, ArH, 1H,), 8.51 (d, ArH, 1H,), 8.54 (dd, ArH, 1H,), 8.61 (d, ArH, 1H,), 8.91 (dd, ArH, 1H,), 10.89 (s, NH, $1 \mathrm{H},), 11.34(\mathrm{~s}, \mathrm{NH}, 1 \mathrm{H},) . \lambda_{\max }=262,344,407,447$ $\left(\varepsilon_{447}=2.85 \times 10^{3}, \varepsilon_{514.5}=0.66 \times 10^{3} \mathrm{Lmol}^{-1} \mathrm{~cm}^{-1}\right)$.

\section{Polymer film preparation}

The homogeneous solutions of poly(amideimide)s in $\mathrm{N}$-methyl-2-pyrrolidinone (NMP) were filtered through $0.2 \mu \mathrm{m}$ membranes and casted onto glass substrates. The films were dried at $100-200^{\circ} \mathrm{C}$ for $4 \mathrm{~h}$. Film thickness was determined with an interference microscope (Tolansky method) and obtained values were in the range of $1.8-3.9 \mu \mathrm{m}$.

\section{Characterization}

FT-IR spectra were recorded on a BIO-RAD FTS 40 A Spectrometer using $\mathrm{KBr}$ pellets. ${ }^{1} \mathrm{H}$ NMR spectroscopy were carried out on a Varian 300 Spectrometer using DMSO- $d_{6}$ as solvent and TMS as the internal standard. Carbon, hydrogen, and nitrogen elemental analyses were performed using Elementar vario EL III. UV-vis spectra were recorded in NMP solution of polymers and as films casted on glass using a Jasco V570 UV-V-NIR spectrometer. Differential scanning calorimetry (DSC) measurements were done using a TA DSC 2010 apparatus with a heating rate of $20^{\circ} \mathrm{C} / \mathrm{min}$ under nitrogen. Thermogravimetric analyses (TGA) were performed on a Paulik-Erdey apparatus at a heating rate of $10^{\circ} \mathrm{C} / \mathrm{min}$ under nitrogen. The reduced viscosity was measured in NMP (concentration $=0.2 \mathrm{~g} / 100 \mathrm{~mL}$ ) at $25^{\circ} \mathrm{C}$ using Ubbelohde viscometer. The molar masses and the dispersities of obtained polymers were determined by size exclusion chromatography (SEC) using RI detector $(\Delta n-2010$ RI WGE Dr. Bures). Measurements were performed in $N, N$-dimethylformamide (DMF) with $5 \mathrm{mmol} / \mathrm{L}$ $\mathrm{LiBr}$ using a set of columns: guard (Polymer Labolatories) + GRAM $100 \AA$ (Polymer Standards Service) $+2 \times$ Mixed-C (Polymer Labolatories). All chromatograms were obtained at $1 \mathrm{~mL} / \mathrm{min}$ at $45^{\circ} \mathrm{C}$. Molar masses were calculated according to polystyrene standards calibration using WINGPC software (PSS). The surface structure of the polymer films after the diffraction gratings were recorded was investigated by atomic force microscope (AFM explorer TMX 2000 apparatus in the contact mode) at room temperature.

\section{Optical Setup}

The experimental setup employed to write the diffraction gratings is shown in Figure 2. All diffraction gratings were recorded at a wavelength $\lambda=514.5 \mathrm{~nm}$ using light beam from an $\mathrm{Ar}^{+}$laser. After splitting the 


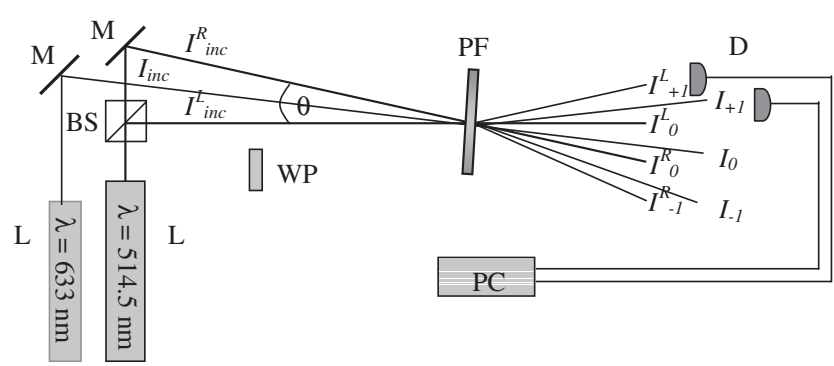

Figure 2. An experimental setup: L - laser, BS - beam splitter, $\mathrm{M}$ - mirror, $\mathrm{W}$ - waveplate $\lambda / 2, \mathrm{PF}-$ sample, $\mathrm{D}$ - detector, $\mathrm{PC}$ - computer.

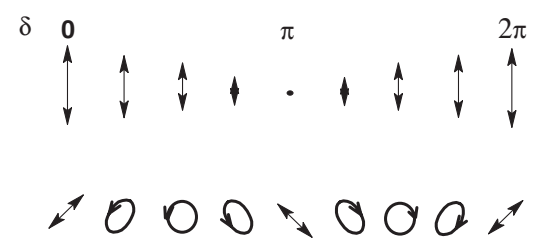

Figure 3. Scheme of light intensity and polarization distribution for experimental grating inscription configurations: (a) $s-s$ and (b) $s-p . \delta$ is the phase shift along the grating wave-vector.

laser beam by a beam splitter into two beams their light intensities were thoroughly equilibrated by inserting an attenuator into one branch. The average total light intensity at the sample was $I_{i n c}^{R}=I_{\text {inc }}^{L}=$ $570 \mathrm{~mW} / \mathrm{cm}^{2}$. The angle between the writing beams was kept fixed at $\theta \cong 20^{\circ}$ resulting in a periodicity of $\Lambda=1.5 \mu \mathrm{m}$ for the grating (according to $\Lambda=\lambda$ / $2 \sin (\theta / 2)$ ). Two different combinations of the writing beam polarizations were realized, i.e., pure intensity modulation one $(s-s)$ and pure polarization with constant intensity over the illuminated region $(s-p)(c f$. Figure 3). In the $s-s$ polarization geometry two incoming beams are linearly polarized with electric field vectors perpendicular to the incidence plane and for $s-p$ polarization one of the incoming beam polarization is rotated by $90^{\circ}$. The grating formation process was monitored by scattering a probe beam from low power He-Ne laser operating at wavelength $\lambda=$ $632.8 \mathrm{~nm}$ on the grating area and observation of the first order diffraction power in the transmission mode. Simultaneously the temporal evolution of the first-order diffraction beam power arising due to self-diffraction process of recording beams was also measured.

\section{RESULTS AND DISCUSSION}

The polymers studied here are amorphous, poly(amideimide)s with methyl substituted azobenzene side group. The chemical structures of the investigated polymers are shown in Figure 1. Polymers PI 1-PI 3 have been reported previously, ${ }^{25}$ however, the diffraction gratings formation in these polymers have not been studied yet. The poly(amideimide)s PI 4 and PI 5 are novel and were prepared from new synthesized dianhydride containing azobenzene group (DA). The ${ }^{1} \mathrm{H}$ NMR and FT-IR spectra of the polymers were consistent with their assigned structures. All polymers exhibited good solubility in a variety of polar solvents such as: NMP, DMA, DMF, DMSO, pyridine and 4-chlorophenol at room temperature. Two polymers PI 3 and PI 5 are soluble in THF, polymer PI 4 is partially soluble and polymers PI 1 and PI 2 are insoluble even after heating in this solvent. The reduced viscosity $\left(\eta_{\mathrm{red}}\right)$ of all investigated polymers is in the range between 0.18 and 0.40 $\mathrm{dL} \mathrm{g}^{-1}$. The new polymer PI 5 showed the highest value of $\eta_{\text {red }}$, i.e., $0.40 \mathrm{dL} \mathrm{g}^{-1}$, polymer PI 4 exhibited reduced viscosity of $0.20 \mathrm{dL} \mathrm{g}^{-1}$. Number-average molecular weights (relative to polystyrene standards) of new polymers for PI $4 M_{\mathrm{n}}$ is $12.8 \times 10^{3}$ and for PI 5 is $19.6 \times 10^{3} \mathrm{~g} / \mathrm{mol}$, with dispersity index between 1.34 (PI 4) and 2.10 (PI 5). The ability of these polymers to form films was examined. Good optical quality films can be obtained by casting from solution on glass substrates. The glass transition temperatures $\left(T_{\mathrm{g}} \mathrm{s}\right)$ of the new polymers (PI 4 and PI 5) and PI 2 were not observed by differential scanning calorimetry (DSC) up to $300{ }^{\circ} \mathrm{C}$. The polymers PI 1 and PI 3 exhibited almost the same $T_{\mathrm{g}}$, i.e., 268 and $269^{\circ} \mathrm{C}$, respectively. Poly(amideimide)s loss $5 \mathrm{wt} \%$ in $\mathrm{N}_{2}\left(T_{\mathrm{d} 5}\right)$ at the temperature range of $330-390^{\circ} \mathrm{C}$. The $T_{\mathrm{d} 5}$ is 336 and $390^{\circ} \mathrm{C}$ for PI 4 and PI 5, respectively. These new polymers PI 4 and PI 5 loss $10 \mathrm{wt} \%\left(T_{\mathrm{d} 10}\right)$ at temperature of 424 and $476^{\circ} \mathrm{C}$.

The kinetics of grating inscription was discussed in relation to the polymer structure, i.e., from the point of view of the chemical structure of the polymer backbone and position in which azobenzene group is attached to the polymer chain. Contrary to polyimides PI 1-PI 3 where azobenzene moiety is introduced between imide rings, in polyimides PI 4 and PI 5 azo chromophore is incorporated between amide linkages.

\section{$U V$-Vis absorption characterizations}

The UV-Vis spectra of the poly(amideimide)s were acquired both in NMP solutions and in films. The range of UV-Vis measurements was limited by transparency of the used solvent and substrate. The optical absorption spectra of the new poly(amideimide)s PI 5, PI 6 and polymer PI 2 in NMP solution are compared in Figure 4. Each spectrum of polymers PI 1-PI 3 consists of two absorption bands: a peak located around $338 \mathrm{~nm}$, characteristic for the benzene rings and band appearing at longer wavelength in the 


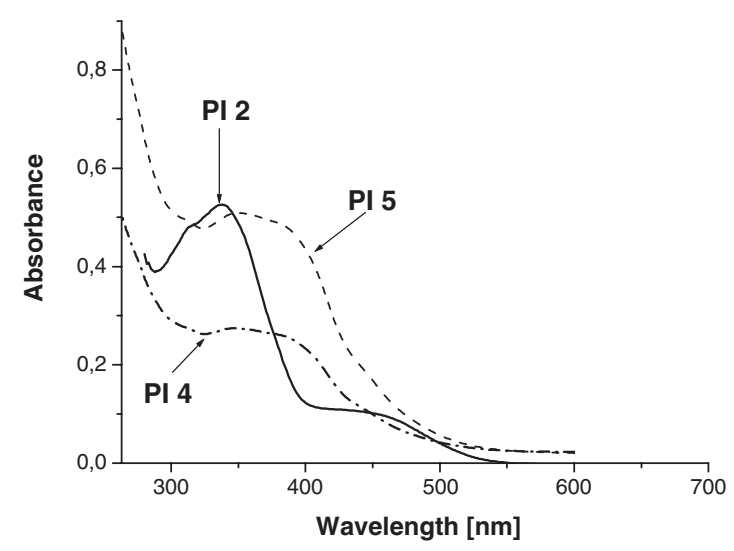

Figure 4. UV-Vis spectra of PI 4, PI 5 and PI 2 in NMP solution. The concentrations are different.

visible range at $455 \mathrm{~nm}$ due to azobenzene group. ${ }^{25}$ Monomer DA shows three absorption maxima at $262,298 \mathrm{~nm}$ attributed to the benzene ring and carbonyl groups and a peak located at $391 \mathrm{~nm}$ which is assigned to the vibronic coupling between $n-\pi^{*}$ and $\pi-\pi^{*}$ electronic transition of the trans azobenzene moiety. ${ }^{33}$ Absorption spectra of polymers obtained from dianhydride DA, i.e., PI 4 and PI 5 exhibit two absorption bands one centered at about $262 \mathrm{~nm}$ and second very broad band at about $334-407 \mathrm{~nm}$ with shoulder. To find the position of the shoulder the second derivatives method was used (i.e., the maximum of the second derivative of absorption corresponds the absorption maximum). The maximum of the shoulder is at $447 \mathrm{~nm}$ for both polymers. The absorption bands at shorter wavelength are due to electronic transitions in polymer backbone while the band at longer wavelength $(447 \mathrm{~nm})$ is attributed to the transitions in azo chromophore. Red shift (about $56 \mathrm{~nm}$ ) of absorption maximum $\left(\lambda_{\max }\right)$ of azobenzene group is observed between poly(amideimide)s PI 4 and PI 5 and the monomer. As expected, both series of poly(amideimide)s, i.e., the polymers P1-P3 and PI 4PI 5 exhibit almost the same position of absorption maxima of azobenzene group because they contain the same azo chromophore with methyl para-substituent. Comparing absorption spectra of series PI 1-PI 3 with series PI 4, PI 5 the differences are observed (Figure 4). These results obviously indicate that the shape of absorption bands is affected by difference in polymer structures, i.e., difference in the chemical surrounding of the azo group in the polymer chain. In other words, the manner in which the group is attached led to a change in the electronic environment of the azobenzene moiety. The spectra of polymer films are compared with spectra obtained in solution. No differences between the position of absorption maximum in film and solution were observed in the case of all polyimides.

\section{Holographic Diffraction Grating Recording}

Irradiation of the azopolymers films by interfering polarized laser beams induces a periodic change in birefringence and/or dichroism in a sample. This result in a diffraction grating build-up as is evidenced by an appearance of a light self-diffraction. We performed measurements of diffraction gratings recording using degenerate two-wave mixing technique (DTWM) with line $\lambda=514.5 \mathrm{~nm}$ of $\mathrm{Ar}^{+}$laser. The experimental setup of DTWM is shown in Figure 2. Diffraction gratings were recorded for two configurations of beams polarization $s-s$ and $s-p$ (Figure 3 ) in different exposure time for each geometry, i.e., up to $60 \mathrm{~min}$ for $s-s$ and $30 \mathrm{~min}$ for the $s-p$ one. Measurements of the temporal evolution of the first-order diffracted beam's power during grating formation enable study of the kinetics of its build-up process and estimation of the diffraction efficiency $\eta$. The latter is defined as the ratio between the first-order diffracted beam intensity $I_{+1}^{L}$ and the input beam intensity $I_{\text {inc }}^{L}$ ( $c f$. Figure 2). Additionally the grating formation process was monitored by $s$-polarized $\mathrm{He}-\mathrm{Ne}$ probe beam operating at wavelength $\lambda=632.8 \mathrm{~nm}$ in the transmission mode and the diffraction efficiency was also measured. Figure 5 shows the exemplary results of both diffraction efficiencies in function of time during grating recording process, i.e., the diffraction efficiency in a self-diffraction of $\mathrm{Ar}^{+}$laser and a diffraction of the probe He-Ne beam, for polymers PI 2 and PI 5 under $s-s$ polarization configuration. As the grating formed, the diffraction efficiency increased, saturated and remained at a constant value throughout the rest of the recording process (Figure 5(a)) at both wavelengths. Such behavior is observed in the polymers containing azobenzene group attached between imide rings (PI 1, PI 2) at $\lambda=514.5 \mathrm{~nm}$. When the azo chromophore is placed between amide groups (PI 4 and PI 5) the diffraction efficiency at $\lambda=514.5 \mathrm{~nm}$ behaves differently (Figure 5(b)). In these polymers diffraction efficiency reached maximum and started to decrease after prolonged exposure. The decreasing in the diffraction efficiency is also observed at $\lambda=632.8 \mathrm{~nm}$ in polymers PI 1, PI 2 and PI 4. Such a different behavior was never observed in the cases of diffraction efficiency measurements performed under $s-p$ geometry. The exemplary measurements of diffraction efficiencies under this geometry are showed in Figure 6 for PI 2. During $s-p$ polarization configuration the kinetics of diffraction efficiencies showed exponential growths which were observed without any exception for all the studied poly(amideimide)s. One interesting thing can be also noticed in Figure 5 when one compares the maximum diffraction efficiencies at two different wavelengths. It is clearly seen that for the polyimide PI 2 the diffraction effi- 
(a)

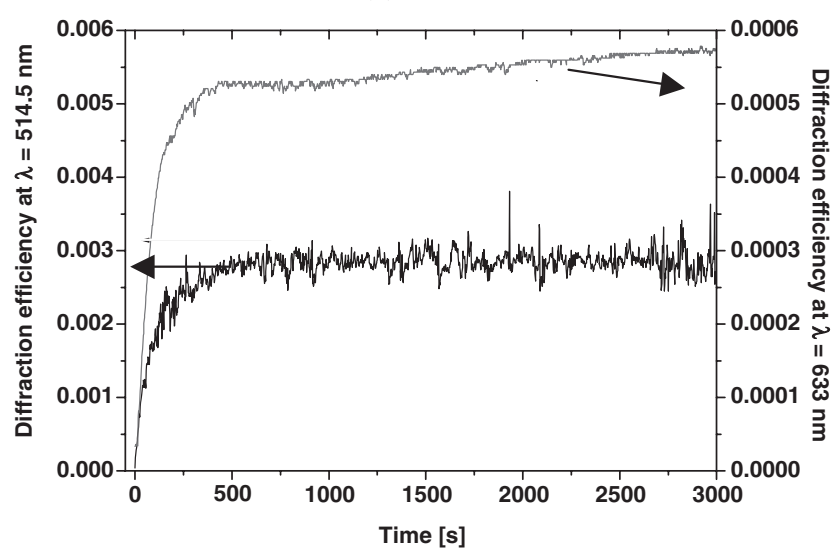

(b)

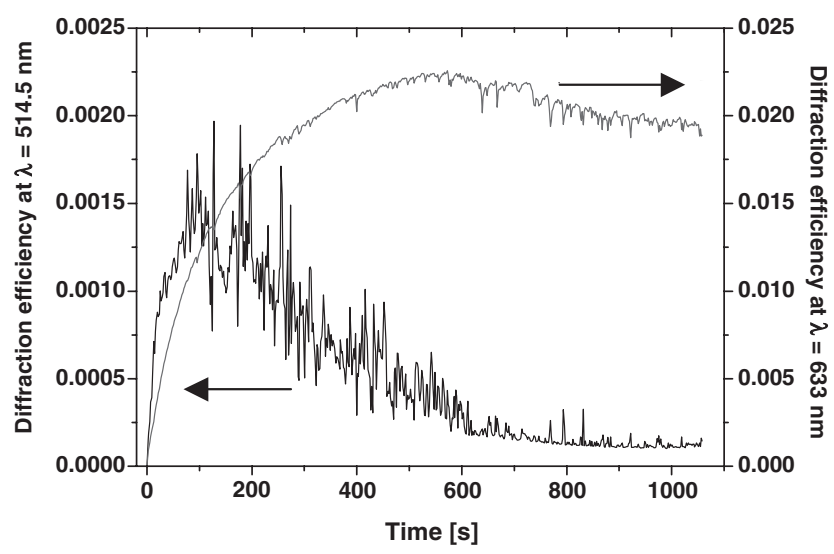

Figure 5. Temporal evolutions of the diffraction efficiencies measured in situ for the inscribed gratings at wavelengths $\lambda=$ $514.5 \mathrm{~nm}$ and $\lambda=632.8 \mathrm{~nm}$ for polyimides PI 2 (a) and PI 5 (b) for $s-s$ polarization configuration.

ciency is significantly higher for laser line $\lambda=514.5$ $\mathrm{nm}$ than for $\lambda=632.8 \mathrm{~nm}$ in contrary to PI 5 case where the maximum diffraction efficiency is inverted, i.e., it is higher for He-Ne laser line. It was also observed for poly(amideimide) PI 1 in comparison to PI 4. Additionally such behavior is independent on configurations of the beams polarization, i.e., the same tendency at which wavelength is the higher diffraction efficiency for each poly(amideimide) is observed for both polarization geometries. The values of the measured diffraction efficiencies for all studied polyimides at those two wavelengths and for both polarization geometries are gathered in Table I. The diffraction efficiency measured at grating recording wavelength $\lambda=514.5 \mathrm{~nm}$ for $s-s$ polarization is generally significantly weaker when compared to $s-p$ one for all studied polyimides. The explanation could be found in the work of Lagugne-Labarthet et al. ${ }^{34}$ where authors claimed that in the case of $s-p$ polarization geometry the birefringence, i.e., modulation of refractive index in the volume of the polymer, is maximal. The differ-

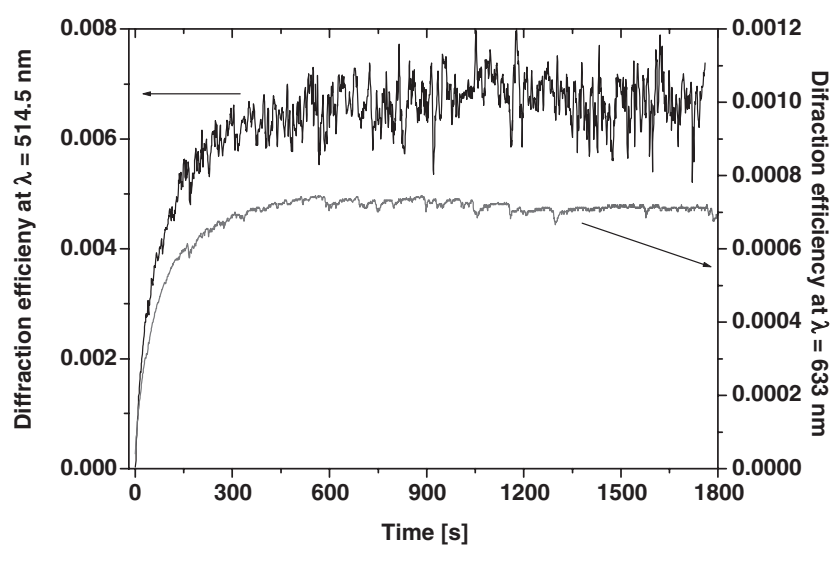

Figure 6. Diffraction efficiencies in function of time for the polyimide PI 2 recorded at different wavelengths $514.5 \mathrm{~nm}$ and $632.8 \mathrm{~nm}$ for $s-p$ polarization geometry.

Table I. Maximum diffraction efficiencies (in \%) measured at two different wavelengths and two polarization configurations for the studied polyimides

\begin{tabular}{cccccc}
\hline \multirow{2}{*}{$\begin{array}{c}\text { Polymer } \\
\text { code }\end{array}$} & \multicolumn{2}{c}{$\mathbf{5 1 4 . 5} \mathbf{~ n m}$} & & \multicolumn{2}{c}{$\mathbf{6 3 2 . 8 \mathbf { n m }}$} \\
\cline { 2 - 3 } \cline { 5 - 6 } & $s-s$ & $s-p$ & & $s-s$ & $s-p$ \\
\hline PI 1 & 0.32 & 0.82 & & 0.12 & 0.08 \\
PI 2 & 0.29 & 0.65 & & 0.06 & 0.07 \\
PI 3 & 0.02 & 0.06 & & 0.11 & 0.15 \\
PI 4 & 1.07 & 1.97 & & 2.63 & 2.78 \\
PI 5 & 0.14 & 0.59 & & 2.23 & 2.45 \\
\hline
\end{tabular}

ence in diffraction efficiency between $s-s$ and $s-p$ configurations is well seen in two-wave mixing experiment but surprisingly much less of difference was observed for reading of these gratings at $\lambda=632.8$ $\mathrm{nm}$ ( $c f$. Table I). In this case the diffraction efficiencies are almost comparable for these both configurations.

In our opinion this difference may result from a specific beam coupling in the case of self-diffraction process (i.e., for $\lambda=514.5 \mathrm{~nm}$ ) especially for $s-p$ polarization grating resulting in large volume changes of refractive index. This type of beam coupling is not present in the case of simple light diffraction on the grating with single beam form He-Ne laser $(\lambda=$ $632.8 \mathrm{~nm})$.

In general the inscribed diffraction gratings show low diffraction efficiencies lying in the range 0.06$2.5 \%$. The lower diffraction efficiencies where observed for polymers with azo group attached between the imide rings (PI 1, PI 2, PI 3), whereas the higher one were observed for polymers with azobenzene group placed between amide groups (PI 4, PI 5). One should not compare the diffraction efficiencies for different sample thickness and unknown surface relief grating contribution to light scattering. How- 
Table II. Parameters of the diffraction efficiency growth curves according to eq 1 obtained from fitting. Recording light wavelength $\lambda=514.5 \mathrm{~nm}$

\begin{tabular}{|c|c|c|c|c|c|c|c|c|}
\hline \multirow{2}{*}{$\begin{array}{l}\text { Polymer } \\
\text { code }\end{array}$} & \multicolumn{4}{|c|}{$s-s$ polarization } & \multicolumn{4}{|c|}{$s-p$ polarization } \\
\hline & $\mathrm{A}_{1}$ & $\tau_{1}[\mathrm{~s}]$ & $\mathrm{A}_{2}$ & $\tau_{2}[\mathrm{~s}]$ & $A_{1}$ & $\tau_{1}[\mathrm{~s}]$ & $\mathrm{A}_{2}$ & $\tau_{2}[\mathrm{~s}]$ \\
\hline PI 1 & 0.03 & 13.5 & 0.02 & 639.6 & 0.07 & 21.8 & 0.02 & 417.6 \\
\hline PI 2 & 0.03 & 16.8 & 0.02 & 146.4 & 0.04 & 11.0 & 0.03 & 128.7 \\
\hline PI 3 & - & - & - & - & 0.01 & 26.9 & 0.01 & 281.0 \\
\hline PI 4 & $0.11^{\mathrm{a}}$ & $83.5^{\mathrm{a}}$ & - & - & 0.08 & 199.9 & 0.06 & 575.5 \\
\hline PI 5 & $0.03^{\mathrm{a}}$ & $13.7^{\mathrm{a}}$ & - & - & 0.04 & 11.8 & 0.04 & 120.4 \\
\hline
\end{tabular}

${ }^{\text {a }}$ Time constant estimated only for the first stage of grating built-up process.

ever, in both cases of bulk refractive index and relief gratings low diffraction efficiencies are due to restricted chromophore's motion in studied polyimides. The azobenzene molecule is rigidly linked to polymer chain because one of the aromatic cores of the azobenzene moiety is a part of the backbone connected in the 2 and 4 position either imide or amide group. The rigid link has a double effect on photoorientation. It makes harder to induce orientation, but on the other side it confers a better stability of photoinduced properties. Taking into account the polymer backbone structure it can be concluded that increase of aliphatic groups amount decreases the value of diffraction efficiency (PI 1, PI 3). This may suggest that stable molecular ordering is more difficult to achieve due to higher chain mobilities.

In order to study the dynamics of the diffraction grating recording, e.g., follow the kinetics of refractive index changes $\Delta n(t)$ and/or surface relief amplitude changes $\Delta d(t)$ the following equation might be applied to describe the grating growth curve:

$\sqrt{\eta(t)}=A_{1}\left[1-\exp \left(-\frac{t}{\tau_{1}}\right)\right]+A_{2}\left[1-\exp \left(-\frac{t}{\tau_{2}}\right)\right]$

where $\eta(t)$ is the measured diffraction efficiency and $\tau_{1}$ and $\tau_{2}$ are the time constants of the fast and slow grating build-up processes contributing to the light diffraction. ${ }^{35}$

The fast process of grating build-up is due to the trans-cis-trans isomerization and the local mobility of azobenzene moiety, which is determined by their size, the free volume around them, and the strength of their coupling to the polymer chain. The slow process depends on the coupling between azobenzene and polymer segments, and the mobility of whole polymer therefore is indirectly connected with surface relief grating formation. Parameters $A_{1}$ and $A_{2}$ tell about the contribution of these processes to light diffraction signal. Such approximation allows to elucidate the dynamics of the involved parameters and make possible to compare the respective grating inscription time constants for all investigated polymers. It is worth to underline the fact that the dependence of inscription rate on the film thickness can be ignored for relatively thick $(>0.5 \mu \mathrm{m})$ films, ${ }^{36}$ what is the case in our work where $d_{0}>1.8 \mu \mathrm{m}$. Therefore the difference of the grating inscription kinetics can predominately be attributed to the polymer structure.

The shape of the square root of diffracted power signal versus time ( $c f$. eq 1 ) for all studied polymers exhibited biexponential behavior under $s-p$ polarization at both wavelengths with one exception for PI 4 where the monoexponential function was more adequate. In some polymers (PI 4, PI 5 at $\lambda=$ $514.5 \mathrm{~nm}$ recording line and PI 1, PI 2, PI 4 at $\lambda=632.8 \mathrm{~nm}$ ) not biexponential kinetics diffraction growth under $s-s$ polarization is observed. In such cases the monoexponential equation was applied to describe the first stages of the grating formation, which gives information about refractive index grating build-up process. The obtained fitting parameters are summarized in Table II for $\lambda=514.5 \mathrm{~nm}$ and in Table III for $\lambda=632.8 \mathrm{~nm}$. Taking into consideration the grating recording under $s-s$ geometry at line $514.5 \mathrm{~nm}$ one could notice the different dynamics behaviors for polymers PI 1 and PI 3 when compared to PI 4 and PI 5 ( $c f$. Figure 5). Polymers with the azobenzene group bounded between imide rings (PI 1, PI 2) showed well described by biexponential function grating growth, i.e., the diffraction efficiency increased, reached the maximum and stayed saturated. The completely different behavior was observed for polymers where the azo moiety was introduced between amide linkages (PI 4, PI 5). In this case the diffraction grating recording process revealed the tendency to the decreasing after reaching the maximum of diffraction efficiency. This behavior can be result of either phase shift $\Delta \varphi(t)$ between birefringence and the surface relief grating $\mathrm{s}^{37}$ or saturation of $c i s$ isomer concentration caused by enhancement of its lifetime at given illumination conditions. If there exist the phase shift between those two gratings (say equal to $\pi$ ) then the build-up of surface relief grating can lead to partial cancellation of light phase retardation caused by the two gratings. This should lead to the de- 
Table III. Parameters of the diffraction efficiency growth curves according to eq 1 obtained from fitting. Scattered light wavelength $\lambda=632.8 \mathrm{~nm}$

\begin{tabular}{|c|c|c|c|c|c|c|c|c|}
\hline \multirow{2}{*}{$\begin{array}{l}\text { Polymer } \\
\text { code }\end{array}$} & \multicolumn{4}{|c|}{$s-s$ polarization } & \multicolumn{4}{|c|}{$s-p$ polarization } \\
\hline & $\mathrm{A}_{1}$ & $\tau_{1}[\mathrm{~s}]$ & $\mathrm{A}_{2}$ & $\tau_{2}[\mathrm{~s}]$ & $\mathrm{A}_{1}$ & $\tau_{1}[\mathrm{~s}]$ & $\mathrm{A}_{2}$ & $\tau_{2}[\mathrm{~s}]$ \\
\hline PI 1 & $0.02^{\mathrm{a}}$ & $20.8^{\mathrm{a}}$ & - & - & 0.02 & 23.7 & 0.01 & 427.9 \\
\hline PI 2 & $0.02^{\mathrm{a}}$ & $74.6^{\mathrm{a}}$ & - & - & 0.01 & 13.0 & 0.01 & 96.4 \\
\hline PI 3 & 0.02 & 28.0 & 0.01 & 586.7 & 0.02 & 16.2 & 0.01 & 142.9 \\
\hline PI 4 & $0.16^{\mathrm{a}}$ & $187.4^{\mathrm{a}}$ & - & - & - & - & 0.18 & 556.2 \\
\hline PI 5 & 0.06 & 11.0 & 0.09 & 128.9 & 0.04 & 5.6 & 0.1 & 112.9 \\
\hline
\end{tabular}

${ }^{a}$ Time constant estimated only for the first stage of grating built-up process.

crease in the diffraction efficiency at the longer exposures. ${ }^{38,39}$

The effect of the backbone structure on the inscription rates of grating formation under $s-p$ polarization in the polymers is also observed. Poly(amideimide)s PI 2 and PI 5 which possess four methyl groups in polymer chain when compared to others revealed the fastest grating recording rates at both wavelengths. The slowest grating formation is observed in PI 4 and PI 1 without methyl groups in polymer backbone. The influence of the type of the group attaching the azobenzene moiety to polymer backbone, i.e., imide or amide, on inscription rates was not pronounced.

\section{Surface Relief Modulation}

As already mentioned the process of holographic diffraction grating recording in azobenzene functionalized polymers is usually accompanied with the creation of the surface relief grating. ${ }^{40}$ The forming mechanisms of the photofabricated SRGs on azopolymer films have been actively investigated by Natansohn et al., Triphaty et al. and others. ${ }^{10,11,19,34,37,41,42}$ The surface relief modulation was found to be dependent on both experimental conditions such as light intensity, the beams polarization and incidence angle, ${ }^{43-47}$ and chemical structures of the polymer backbone and the azobenzene group, the polymer molecular weight. ${ }^{19,45,48,49}$ The surface grating formation ability was tested by atomic force microscopy (AFM) for all investigated polyimides. AFM scans were taken for a $20 \mu \mathrm{m} \times 20 \mu \mathrm{m}$ area of the grating. The original film surfaces before exposure were planar without any regular periodicity. The results of AFM examination are presented in Figure 7 for exemplary polyimide PI 5 for $s-s$ and $s-p$ polarization configurations. We confirmed that also for the group of studied polymer the surface relief formation is strongly dependent on the writing beam polarizations. After grating recording under $s-s$ polarization configuration the surface of the polyimides films showed a regularly spaced relief structures with the grating spacing of about $1.5 \mu \mathrm{m}$, as it was set by the interference pattern ( $c f$. Figure 7(a),(b)). The grating profile exhibits a nicely sinusoidal shape ( $c f$. Figure 7(b)) and relief amplitude is about $25 \mathrm{~nm}$ for PI 5. The surface relief grating inscribed under $s-p$ geometry shows spatially more dense structure (halfperiod) and much less relief amplitude lower than $4 \mathrm{~nm}(c f$. Figure 7(c),(d)). This appearance of halfperiod structure may result of additional interference between two $p$-polarized beams of 0 -th and 2-nd order during $s-p$ inscription. ${ }^{50,51}$ Figure 7 depicts the general rule of surface modulation in dependence of writing beams polarization in all studied poly(amideimide)s. It means that in the case of $s-s$ geometry the regularly sinusoidal, relatively deep modulation is observed, whereas for $s-p$ polarization configuration the surface modulation is very weak and the half-period grating appears. Detailed modeling of such phenomenon will be described in a prepared separate paper. ${ }^{51}$

The measurements of surface modulation depths for gratings recorded for $s-s$ polarization of the interfering beams in the studied series of polymers are compared in Figure 8. The results are somehow surprising because the higher amplitude of the surface modulation does not correspond to the higher diffraction efficiency ( $c f$. Table I). According to the theory, ${ }^{34,44}$ which was also experimentally proved it the same references, such correlation should be observed. Our results are significantly different and we cannot find now the convincing reason for such behavior except that the absorption and phase shift between the gratings play a decisive role. Anyway it should be stressed that in spite of low diffraction efficiencies it is possible to inscribe regular surface gratings on the polymer films of studied polymers. One clear conclusion about the surface relief formation ability in studied polymers can be made. For the same experimental conditions the deeper surface modulation is achieved in poly(amideimide)s with azobenzene group introduced between imide rings. It is well known that the surface grating depth can be controlled by the light exposure time, the polarization state of the beams (e.g., using circular polarizations) and the period. Thus, SRG's with higher amplitude of surface modulation can be inscribed in 
(a)
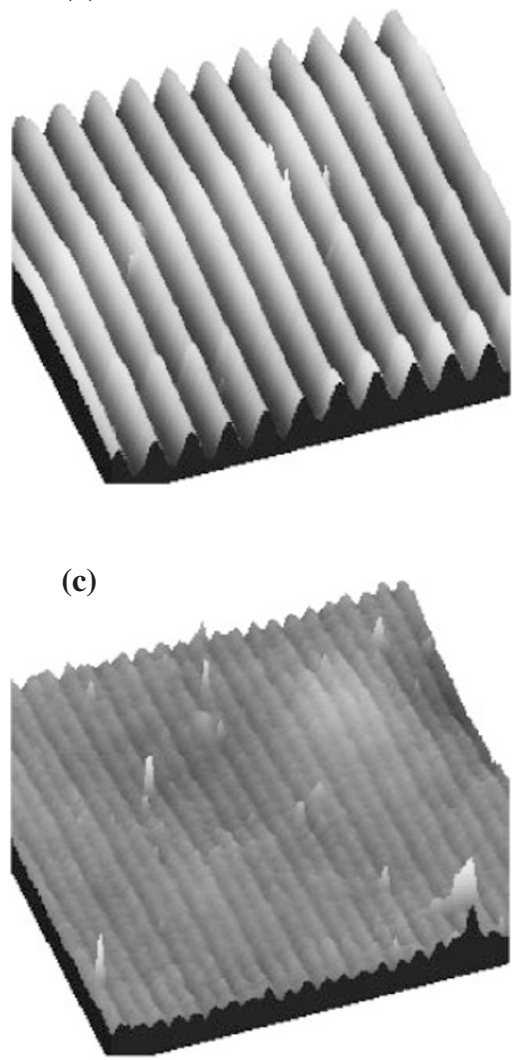

(b)

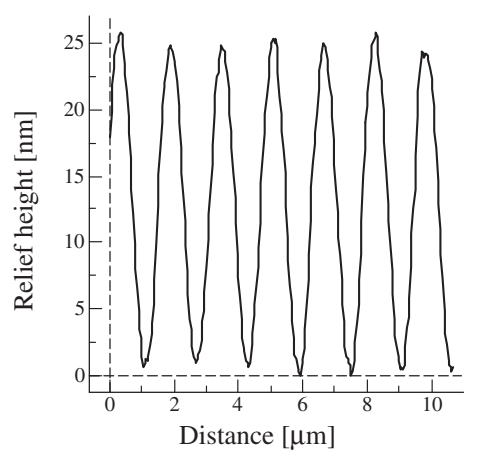

(d)

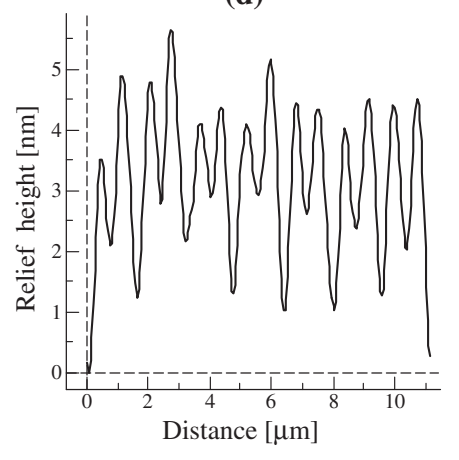

Figure 7. AFM surface imaging of SRG written in $3.5 \mu \mathrm{m}$ thick film of PI 5: three-dimensional topography of surface relief grating inscribed with $s$-s polarized interfering beams (a) and its amplitude modulation profile (b) three-dimensional topography of surface relief grating inscribed with $s$ - $p$ polarization configuration (c) and its amplitude modulation profile along the ripple pattern (d).

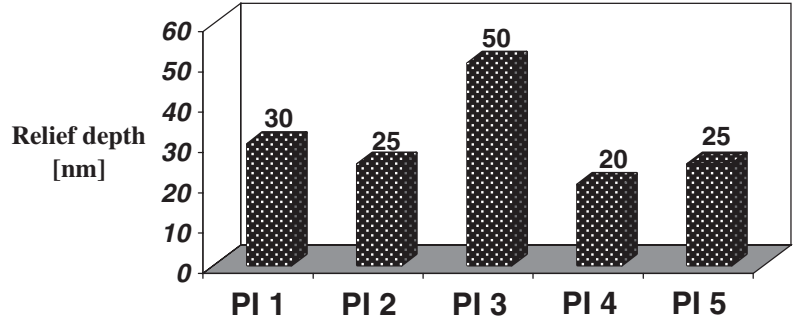

Figure 8. The surface relief depths obtained in studied polyimide films under $s-s$ polarization configuration of recording beams.

investigated polyimide films by tuning experimental conditions.

As a further step in this work the thermal stability of SRG was investigated. The thermal behavior of recorded gratings at elevated temperatures is an important parameter of a given polymeric material. Shape stability is greatly desired in photonic applications such as waveguide couplers and aligning layers for liquid crystals. ${ }^{52}$ Most surface relief gratings are thermally erasable. It has been recognized that the shape stability of the relief structure is strongly associated with the rigidity of the polymer main chain. ${ }^{18,36,52}$
Therefore it is expected that SRGs in studied polyimides should be stable even at elevated temperatures. In order to detect the effect of the temperature on the stability of the surface modulation the polymers films were heated at $200{ }^{\circ} \mathrm{C}$ from 15 to $60 \mathrm{~min}$. After annealing the film surface was examined again by AFM technique. The negligible $(<1 \%)$ changes in the amplitudes of the surface relief grating after $15 \mathrm{~min}$ of the thermal treatment were observed in all poly(amideimide)s with one exception. In polymer PI 3 the decrease in the relief amplitude took place after the first $15 \mathrm{~min}$ of heating from $50 \mathrm{~nm}$ to $20 \mathrm{~nm}$. Figure 9 shows the surface topography of the polymer PI 2 film before and after $60 \mathrm{~min}$ of thermal treatment at $200^{\circ} \mathrm{C}$. The grating depths remain unchanged after 60 min of heating. Similarly no surface relief deformation after annealing of the inscribed gratings was observed in the rest of studied polyimides. The heating has no effect on the grating spacing.

\section{CONCLUSIONS}

The ability of the holographic grating recording in series of side-chain azoaromatic poly(amideimide)s was studied. The linking place of the azobenzene units 

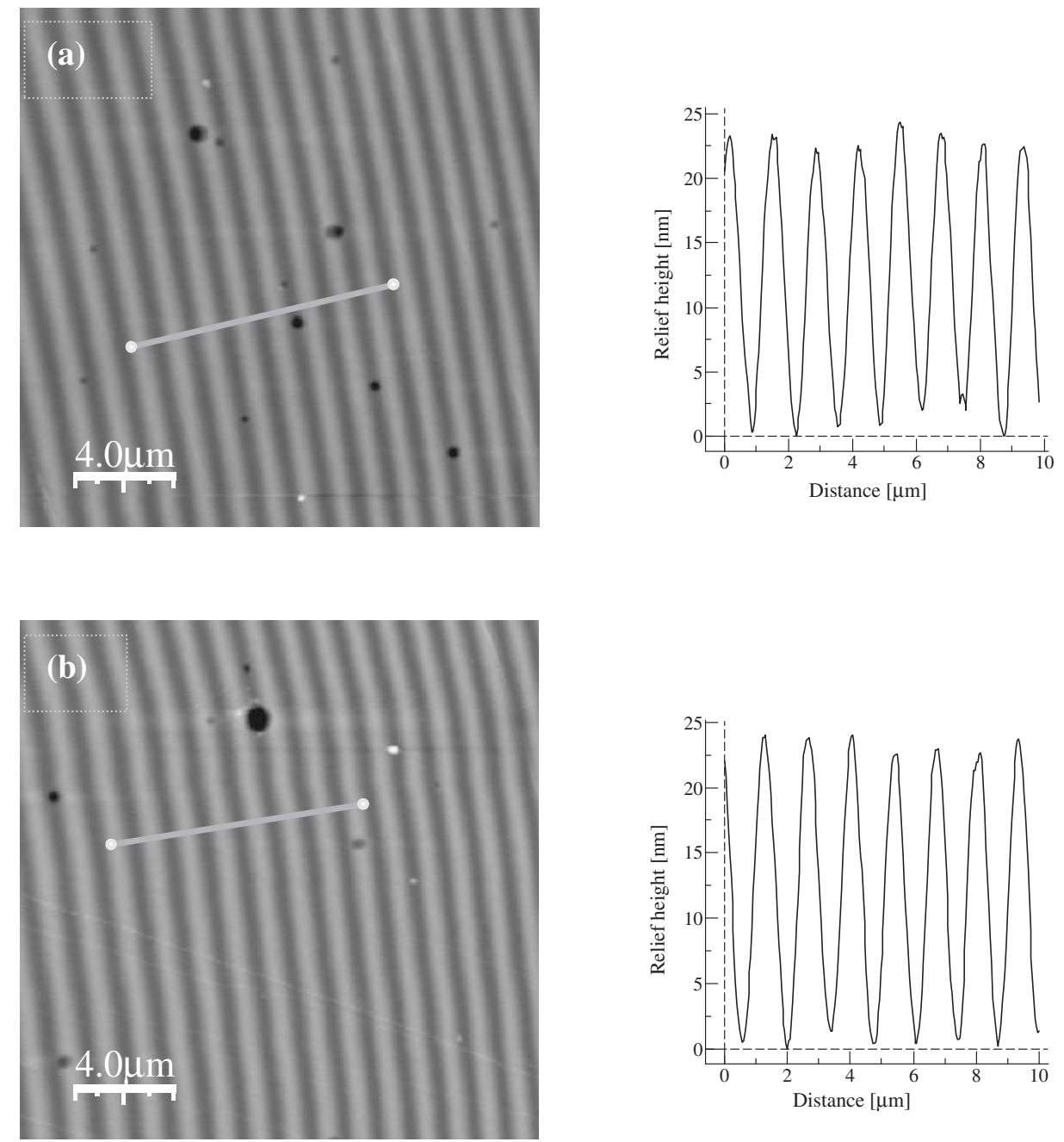

Figure 9. The topographical AFM images of relief gratings observed in $1.8 \mu \mathrm{m}$ thick PI 2 film before (a) and after thermal treatment at $200^{\circ} \mathrm{C}$ for $60 \mathrm{~min}(\mathrm{~b})$.

in polymer chain and the backbone structure exhibited some effect on the inscription rates and the values of diffraction efficiencies. The highest values of diffraction efficiencies showed polymer with azobenzene chromophores attached between amide linkages to polymer. The faster grating recording rates were observed for poly(amideimide)s with four methyl substituents in the backbone. The diffraction efficiency of light scattered on the gratings was dependent on used light wavelength. We noticed that polymers with the azobenzene group attached between imide rings had higher diffraction efficiency for the wavelength $514.5 \mathrm{~nm}$ than for $632.8 \mathrm{~nm}$ whereas polyimides with the azo group placed between amide groups exhibited opposite behavior. However, the origin of this phenomenon may not be directly linked with the molecular structure. In spite of the observed low diffraction efficiency it was possible to inscribe surface relief gratings of amplitudes reaching $50 \mathrm{~nm}$ on poly(amideimide)s films using $s-s$ light polarization configuration. The studies confirmed the strong depend- ency of writing beams polarization on the efficiency of the surface modulation. The sinusoidal modulation was observed for $s-s$ recording, whereas the halfperiod structure has been seen for $s-p$ geometry. The significant differences in the SRG modulation depths were observed. The deeper surface modulation $(s-s$ case) was achieved in polymers with azobenzene group introduced between imide rings. The photoinduced surface gratings were partially erasable by heating at elevated temperature.

Due to ease of surface relief gratings recording on the azo functionalized poly(amideimide) films, such polymers may found potential applications in fabrication of optical elements and devices.

Acknowledgment. The authors would like to thank MSc L. Grobelny for NMR analysis and MSc B. Hajduk for measurements of film thickness. A.S. and A.M wish to thank the Polish Ministry of Education and Science for the financial support under grant no 3 T08E 07629 and N507 132 31/3302. 


\section{REFERENCES}

1. O. Ostroverkhova and W. E. Moerner, Chem. Rev., 104, 3267 (2004).

2. S. K. Yesodha, Ch. K. S. Pillai, and N. Tsutsumi, Prog. Polym. Sci., 29, 45 (2004).

3. S. Xie, A. Natansohn, and P. Rochon, Chem. Mater., 5, 403 (1993).

4. J. A. Delaire and K. Nakatani, Chem. Rev., 100, 1817 (2000).

5. A. Natansohn and P. Rochon, Chem. Rev., 102, 4139 (2002).

6. S. Yang, K. Yang, L. Niu, R. Nagarajan, S. Bian, A. K. Jain, and J. Kumar, Adv. Mater., 16, 693 (2004).

7. C. Cojocariu and P. Rochon, Macromolecules 38, 9526 (2005).

8. I. Zebger, M. Rutloh, U. Hoffman, J. Stumpe, H. W. Siesler, and S. Hvilsed, J. Phys. Chem. A, 106, 3454 (2002).

9. T. Todorov, L. Nikolova, and N. Tomova, Appl. Opt., 23, 4309 (1984).

10. P. Rochon, E. Batalla, and A. Natansohn, Appl. Phys. Lett., 66, 139 (1995).

11. D. Y. Kim, S. K. Tripathy, L. Li, and J. Kumar, Appl. Phys. Lett., 66, 1166 (1995).

12. Y. Zhao, Pure Appl. Chem., 76, 1499 (2004).

13. F. Lagugne-Labarthet, J. L. Bruneel, V. Rodriguez, and C. Courisseau, J. Phys. Chem. B, 108, 1267 (2004).

14. P. Rochon, A. Natansohn, C. L. Callender, and L. Robitaille, Appl. Phys. Lett., 71, 1008 (1997).

15. J. Paterson, A. Natansohn, C. L. Callender, and L. Robitaille, Appl. Phys. Lett., 69, 3318 (1996).

16. R. J. Stockermans and P. L. Rochon, Appl. Optics, 38, 3714 (1999).

17. O. N. Oliveira Jr., D. S. dos Santos Jr., D. T. Balogh, V. Zucolotto, and C. R. Mendonca, Adv. Colloid Interface Sci., 116, 179 (2005).

18. Y. Wu, A. Natansohn, and P. Rochon, Macromolecules, 34, 7822 (2001).

19. Y. He, X. Wang, and Q. Zhou, Polymer, 43, 7325 (2002).

20. J. P. Chen, F. Lagugne-Labarthet, A. Natansohn, and P. Rochon, Macromolecules, 32, 8572 (1999).

21. S. Zhang, Y. Li, D. Yin, X. Wang, X. Zhao, Y. Shao, and S. Yang, Eur. Polym. J., 41, 1079 (2005).

22. J. Fang, X. Guo, S. Harada, T. Watari, K. Tanaka, H. Kita, and K. Okamoto, Macromolecules, 35, 9022 (2002).

23. J.-Y. Lee, Ch. S. Baek, and E.-J. Park, Eur. Polym. J., 41, 2107 (2005).

24. W. Leng, Y. Zhou, Q. Xu, and J. Liu, Macromolecules, 34, 4774 (2001).

25. E. Schab-Balcerzak, B. Sapich, and J. Stumpe, Polymer, 46, 49 (2005).

26. D. Sek, E. Schab-Balcerzak, M. Solyga, and A. Miniewicz, Synth. Met., 9123, 1 (2001).

27. A. Miniewicz, K. Komorowska, D. Sek, E. SchabBalcerzak, and M. Solyga, Pol. J. Chem., 76, 395 (2002).

28. E. Schab-Balcerzak, D. Sek, B. Jarzabek, Y. Zakrevskyy, and J. Stumpe, High Perform. Polym., 16, 585 (2004).
29. E. Schab-Balcerzak, B. Sapich, R. Hass, and J. Stumpe, Proceedings of SPIE, 5724, 301 (2005).

30. E. Schab-Balcerzak, B. Sapich, J. Stumpe, A. Sobolewska, and A. Miniewicz, e-Polymers, 021 (2006) (http://www. e-polymers.org/).

31. E. Schab-Balcerzak, L. Grobelny, A. Sobolewska, and A. Miniewicz, Eur. Polym. J., 42, 2859 (2006).

32. D. Sek, E. Schab-Balcerzak, and E. Grabiec, Polymer, 40, 2419 (1999).

33. G. Iftime, F. Lagugne-Labarthet, A. Natansohn, P. Rochon, and K. Murti, Chem. Mater., 14, 168 (2002).

34. F. Lagugne-Labarthet, T. Buffeteau, and C. Sourisseau, J. Phys. Chem. B, 103, 6690 (1999).

35. M. S. Ho, A. Natansohn, and P. Rochon, Macromolecules, 28, 6124 (1995).

36. T. Fukuda, H. Matsuda, T. Shiraga, T. Kimura, M. Kato, N. K. Viswanathan, J. Kumar, and S. K. Tripathy, Macromolecules, 33, 4220 (2000).

37. F. Lagugne-Labarthet, T. Buffeteau, and C. Sourisseau, $J$. Phys. Chem., 102, 2654 (1998).

38. N. Reinke, A. Draude, T. Fuhrmann, H. Franke, R. A. Lessard, Appl. Phys. B: Lasers Opt., 78, 205 (2004).

39. A. Sobolewska and A. Miniewicz, J. Phys. Chem. B, 111, 1536 (2007).

40. P. Varhegyi, A. Kerekes, S. Sajti, F. Ujhelyi, P. Kopa, G. Szavas, and E. Lornicz, Appl. Phys. B: Lasers Opt., 76, 397 (2003).

41. O. N. Oliveira Jr., L. Li, J. Kumar, and S. Tripahty, in "Photoreactive Organic Thin Films," Z. Sekkat, W. Knoll, Ed., Academic Press, San Diego, 2002, p 429.

42. D. Y. Kim, L. Li, X. L. Jiang, V. Shivshankar, J. Kumar, and S. K. Tripathy, Macromolecules, 28, 8835 (1995).

43. Ch. J. Barrett, A. L. Natansohn, and P. L. Rochon, J. Phys. Chem., 100, 8836 (1996).

44. S. K. Tripathy, N. K. Viswanathan, S. Balasubramanian, S. Bian, L. Li, and J. Kumar, in "Multiphoton and Light Driven Multielectron Processes in Organics: New Phenomena, Materials and Application," F. Kajzar and M. V. Agranovich, Ed., NATO Science Series: High Technology, Dordrecht, 3, 2000, Vol. 79, p 421.

45. N. K. Viswanathan, D. Y. Kim, S. Bian, J. Williams, W. Liu, L. Li, L. Samuelson, J. Kumar, and S. K. Tripathy, J. Mater. Chem., 9, 1941 (1999).

46. X. L. Jiang, L. Li, J. Kumar, D. Y. Kim, V. Shivshankar, and S. K. Tripathy, Appl. Phys. Lett., 68, 2618 (1996).

47. S. Yoneyama, T. Yamamoto, O. Tsutsumi, A. Kanazawa, T. Shiono, and T. Ikeda, Macromolecules, 35, 8751 (2002).

48. M. Helgert, L. Wenke, S. Hvilsted, and P. S. Ramanujam, Appl. Phys. B: Lasers Opt., 72, 429 (2001).

49. W. Liu, S. H. Lee, S. Yang, S. Bian, L. Li, L. A. Samuelson, J. Kumar, and S. K. Tripathy, J. Macromol. Sci., Part A: Pure Appl. Chem., 38, 1355 (2001).

50. F. Lagugne-Labarthet, T. Buffeteau, and C. Sourisseau, $J$. Appl. Phys., 90, 3149 (2001).

51. A. Sobolewska and A. Miniewicz, in preparation.

52. N. Zettsu and T. Seki, Macromolecules, 37, 8692 (2004). 